This article was downloaded by: [Universiteit Leiden / LUMC]

On: 06 June 2015, At: 05:41

Publisher: Routledge

Informa Ltd Registered in England and Wales Registered Number: 1072954 Registered

office: Mortimer House, 37-41 Mortimer Street, London W1T 3JH, UK

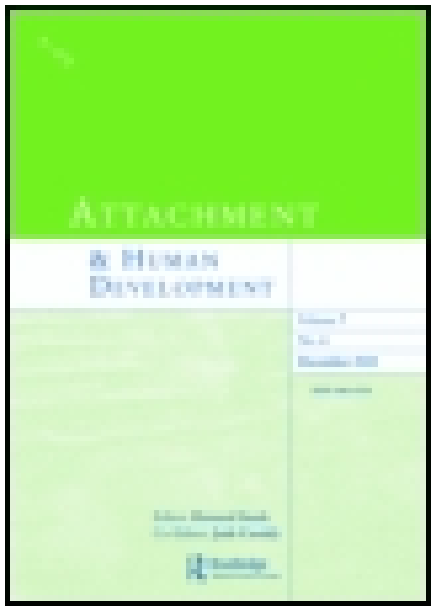

CrossMark

Click for updates

\section{Attachment \& Human Development}

Publication details, including instructions for authors and subscription information:

http://www.tandfonline.com/loi/rahd20

\section{Adult Attachment Interview differentiates adolescents with Childhood Sexual Abuse from those with clinical depression and non- clinical controls}

Marie-José van Hoof ${ }^{\mathrm{abc}}$, Natasja D.J. van Lang ${ }^{\mathrm{bc}}$, Sandra Speekenbrink ${ }^{\mathrm{e}}$, Marinus H. van IJzendoorn ${ }^{\text {cdf }} \&$ Robert R.J.M. Vermeiren $^{\text {bcg }}$

a Psychotraumacenter and Department of Child and Adolescent Psychiatry, GGZ Kinderen en Jeugd Rivierduinen, Leiden, The Netherlands

${ }^{b}$ Curium-LUMC, Department of Child and Adolescent Psychiatry, Leiden University Medical Center, Leiden, The Netherlands

c Leiden Institute of Brain and Cognition (LIBC), Leiden University, Leiden, The Netherlands

d Department of Child and Family Studies, Faculty of Social Sciences, Leiden University, Leiden, The Netherlands

e GGNet Jeugd, Doetinchem, The Netherlands

f School for Pedagogical and Educational Sciences, Erasmus University, Rotterdam, The Netherlands

${ }^{g}$ Department of Forensic Youth Psychiatry De Bascule, VU University Medical Center, Amsterdam, The Netherlands Published online: 05 Jun 2015.

To cite this article: Marie-José van Hoof, Natasja D.J. van Lang, Sandra Speekenbrink, Marinus H. van IJzendoorn \& Robert R.J.M. Vermeiren (2015): Adult Attachment Interview differentiates adolescents with Childhood Sexual Abuse from those with clinical depression and non-clinical controls, Attachment \& Human Development, DOI: 10.1080/14616734.2015.1050420

To link to this article: http://dx.doi.org/10.1080/14616734.2015.1050420 
Taylor \& Francis makes every effort to ensure the accuracy of all the information (the "Content") contained in the publications on our platform. However, Taylor \& Francis, our agents, and our licensors make no representations or warranties whatsoever as to the accuracy, completeness, or suitability for any purpose of the Content. Any opinions and views expressed in this publication are the opinions and views of the authors, and are not the views of or endorsed by Taylor \& Francis. The accuracy of the Content should not be relied upon and should be independently verified with primary sources of information. Taylor and Francis shall not be liable for any losses, actions, claims, proceedings, demands, costs, expenses, damages, and other liabilities whatsoever or howsoever caused arising directly or indirectly in connection with, in relation to or arising out of the use of the Content.

This article may be used for research, teaching, and private study purposes. Any substantial or systematic reproduction, redistribution, reselling, loan, sub-licensing, systematic supply, or distribution in any form to anyone is expressly forbidden. Terms \& Conditions of access and use can be found at http://www.tandfonline.com/page/termsand-conditions 


\title{
Adult Attachment Interview differentiates adolescents with Childhood Sexual Abuse from those with clinical depression and non-clinical controls
}

\author{
Marie-José van Hoof ${ }^{\mathrm{a}, \mathrm{b}, \mathrm{c} *}$, Natasja D.J. van Lang ${ }^{\mathrm{b}, \mathrm{c}}$, Sandra Speekenbrink ${ }^{\mathrm{e}}$, \\ Marinus H. van IJzendoorn ${ }^{\mathrm{c}, \mathrm{d}, \mathrm{f}}$ and Robert R.J.M. Vermeiren ${ }^{\mathrm{b}, \mathrm{c}, \mathrm{g}}$ \\ ${ }^{a}$ Psychotraumacenter and Department of Child and Adolescent Psychiatry, GGZ Kinderen en Jeugd \\ Rivierduinen, Leiden, The Netherlands; ${ }^{b}$ Curium-LUMC, Department of Child and Adolescent \\ Psychiatry, Leiden University Medical Center, Leiden, The Netherlands; ${ }^{c}$ Leiden Institute of Brain \\ and Cognition (LIBC), Leiden University, Leiden. The Netherlands; ${ }^{d}$ Department of Child and \\ Family Studies, Faculty of Social Sciences, Leiden University, Leiden, The Netherlands; ${ }^{e}$ GGNet \\ Jeugd, Doetinchem, The Netherlands; ${ }^{f}$ School for Pedagogical and Educational Sciences, Erasmus \\ University, Rotterdam, The Netherlands; ${ }^{g}$ Department of Forensic Youth Psychiatry De Bascule, VU \\ University Medical Center, Amsterdam, The Netherlands
}

(Received 15 January 2015; accepted 7 May 2015)

\begin{abstract}
Although attachment representation is considered to be disturbed in traumatized adolescents, it is not known whether this is specific for trauma, as comparative studies with other clinical groups are lacking. Therefore, attachment representation was studied by means of the Adult Attachment Interview in adolescents with Childhood Sexual Abuse (CSA) $(N=21)$, clinical depression $(N=28)$ and non-clinical controls $(N=28)$. Coherence of mind and unresolved loss or trauma, as well as the disorganized attachment classification differentiated the CSA group from the clinical depression group and controls, over and above age, IQ, and psychiatric symptomatology. In the current era of sustained criticism on criteria-based classification, this may well carry substantial clinical relevance. If attachment is a general risk or vulnerability factor underlying specific psychopathology, this may guide diagnostic assessment as well as treatment.
\end{abstract}

Keywords: attachment representation; Childhood Sexual Abuse; clinical depression; dissociation; unresolved loss or trauma; coherence of mind

\section{Introduction}

Adolescents who experienced trauma in their lives are suggested to have a different attachment representation than their peers who did not (e.g. Cassidy \& Mohr, 2001; Liotti, 2004; Lyons-Ruth, Dutra, Schuder, \& Bianchi, 2006). Attachment representation refers to the way one conceives and narrates the relationship with his or her parents or caretakers. It is suggested that traumatized adolescents are characterized by high rates of insecure and unresolved-disorganized attachment representations due to the impact of trauma on their lives (e.g. Lyons-Ruth et al., 2006). For instance, they may idealize or deny the importance of the relationship with their caretakers (dismissive attachment representation), they may be preoccupied with anger and fear (preoccupied attachment representation), they might be unresolved for loss of attachment figures or traumatic experiences (unresolved attachment representation), or they

*Corresponding author. Email: HoofM@rivierduinen.nl 
express all of these signs of insecure and unresolved-disorganized attachment at the same time (Hesse, 2008; Neufeld Bailey, Moran, \& Pederson, 2007). In all of these instances the coherence of the narrative, called coherence of mind, is moderate to very low.

Surprisingly few studies have investigated attachment representations in clinical groups of adolescents with and without a history of trauma (for a meta-analysis see Bakermans-Kranenburg \& van IJzendoorn, 2009). Studying attachment representations in specific clinical groups could add to a better understanding and (differential) diagnosis of their symptomatology. This is especially the case for adolescents who experienced Childhood Sexual Abuse (CSA), as they are likely to have severe anxiety and depressive symptoms, besides post-traumatic stress and dissociative symptoms (e.g. Cicchetti \& Toth, 1995; Cloitre et al., 2009; Pollak \& Kistler, 2002). Thus, adolescents with clinical depression, who exhibit a mix of depressive and anxious symptoms, are of particular interest as a comparison group for adolescents with CSA, because of partially overlapping symptomatology. The aim of this paper is to determine whether attachment representations differentiate adolescents with CSA from clinically depressed adolescents and matched controls beyond psychiatric symptom assessment.

CSA is defined as "any form of child abuse in which an adult or older adolescent uses a child for sexual stimulation" (see committee of the American Psychological Association Board of Professional Affairs, 2013, p. 30), using the third National Incidence Study (NIS-3) operationalized definitions of CSA Specific Form of Maltreatment (NIS-3 code; Sedlak, 2001; see Appendix A in Stoltenborgh, van IJzendoorn, Euser, \& BakermansKranenburg, 2011). As self-reported CSA prevalence worldwide is found to be one in 10 youths (Stoltenborgh et al., 2011), it can be considered a serious global mental health problem. Sustained, repeated and cumulative traumas, as often occur in CSA, can go along with a myriad of depressive, anxious, dissociative, externalizing and post-traumatic stress symptoms (Fergusson, McLeod, \& Horwood, 2013; Gospodarevskaya, 2013; KimSpoon, Cicchetti, \& Rogosch, 2013). From the nature of CSA, adolescents who experienced this adversity are at risk for lifelong psychosocial and somatic problems (Anda et al., 2006; McCrory, De Brito, \& Viding, 2012; Teicher \& Samson, 2013), through direct consequences of the abuse and indirect, epigenetic changes (Caspi et al., 2002; McGowan et al., 2009). This increases the likelihood of transgenerational transmission of sexual abuse and (psycho)pathology (McCloskey \& Bailey, 2000; Putnam, 2003). Given this detrimental impact of CSA on one's life, it is important to identify underlying general pathogenic factors, such as incoherent or unresolved (Ud) attachment representations, that might provide clues for better diagnostics and treatment. We expect unresolved loss or trauma to be a stronger indicator of CSA than lack of coherence as the latter might also be observed in narratives about adverse past or current attachment experiences without specific losses or trauma.

Abuse and neglect have also been associated with contradictory attachment strategies within the same narrative (the "cannot classify" attachment classification, CC; Hesse, 2008; Neufeld Bailey et al., 2007) and with pervasive fear throughout attachment narratives of the Adult Attachment Interview (AAI, the so-called E3 classification; Main, Kaplan, \& Cassidy, 1985; Turton, McGauley, Marin-Avellan, \& Hughes, 2001). These classifications have been associated with diverse psychiatric disorders in adults such as PTSD (Harari et al., 2009), borderline personality disorder (Agrawal, Gunderson, Holmes, \& Lyons-Ruth, 2004; Barone, Fossati, \& Guiducci, 2011; Lyons-Ruth, Brumariu, Bureau, Hennighausen, \& Holmes, 2014; Lyons-Ruth, Bureau, Holmes, Easterbrooks, \& Brooks, 2013), and anti-social personality disorder (Levinson \& Fonagy, 2004; van IJzendoorn 
et al., 1997). In all of these instances the coherence of the narrative, called coherence of mind, is low. Because Ud, CC and E3 classifications may all be caused by underlying loss and/or trauma experiences in the Main, Goldwyn, and Hesse (2003) coding system, we will examine their associations with trauma in adolescents who suffer from sexual abuse experiences or struggle with clinical depression, and with typically developing peers.

We are aware of alternative or complementary classification systems to describe attachment representations of traumatized individuals. For example, Lyons-Ruth and colleagues (e.g. Lyons-Ruth, 2003; Lyons-Ruth, Melnick, Patrick, \& Hobson, 2007; Lyons-Ruth \& Spielman, 2004) developed the hostile/helpless (HH) category to explain why some nontraumatized mothers have disorganized children. Mothers who were not judged unresolved nevertheless manifested a pervasive sense of hostility or helplessness throughout the AAI transcript. This appeared to be based on childhood experiences of lack of attunement in parent-child interactions, role-reversal (Vulliez-Coady, Obsuth, Torreiro-Casal, Ellertsdottir, \& Lyons-Ruth, 2013), and emotional neglect (Milot et al., 2014). Also, childhood loss and trauma were found to be differentially associated with maternal unresolved and hostile-helpless states of mind (Lyons-Ruth, Yellin, Melnick, \& Atwood, 2003). How both coding systems (Lyons-Ruth, Bronfman, \& Parsons, 1999; Main et al., 2003) are interrelated was studied in low risk, poor and maltreating mothers (Frigerio, Costantino, Ceppi, \& Barone, 2013). The authors found $\mathrm{HH}$ profiles not to overlap with Ud, CC and E3 categories. In the current study we focus on the more frequently used and well-validated Main et al. (2003) coding system to facilitate comparison with previous (clinical) studies on attachment (Bakermans-Kranenburg \& van IJzendoorn, 2009). It should also be noted that the AAI does not assess (reactive) attachment disorders as defined by the DSM-IV or DSM-5 (for the differences, see van IJzendoorn \& Bakermans-Kranenburg, 2003; Zeanah \& Smyke, 2008).

For several reasons, there is need to study attachment issues in adolescence, in particular in clinical samples. First, puberty is known to be accompanied by emotion regulation and parent-child interaction problems, which might exacerbate emerging clinical issues (Blakemore, 2012; Obsuth, Hennighausen, Brumariu, \& Lyons-Ruth, 2014). Secondly, several psychiatric disorders, like clinical depression, become only clearly visible in adolescence (Paus, Keshavan, \& Giedd, 2008). Thirdly, CSA has a high incidence in adolescence (Bicanič, 2014) and is often accompanied by PTSD. Thus, especially in female adolescents, depressive and anxiety disorders and CSA-related PTSD coincide (Bersani et al., 2014; Bicanič, 2014; Christiansen \& Hansen, 2015), making it vital to disentangle disorder-specific from general psychiatric symptoms. In contrast to the extensive literature on attachment in the general population, the small number of studies on the association of attachment with specific psychiatric disorders is surprising (e.g. Allen, 2008; Dozier, Chase Stovall-McClough, \& Albus, 2008; Duchesne \& Ratelle, 2014; Nelson, Westerlund, Martin McDermott, Zeanah, \& Fox, 2013; Wallis \& Steele, 2001; Waters, Merrick, Treboux, Crowell, \& Albersheim, 2000). The few clinical studies have focused on infants, institutionalized children or adult samples (e.g. Bentovim, Cox, Bingley Miller, \& Pizzey, 2009; Fonagy et al., 1996; MacKinnon, 2012; Strathearn, 2011; Zeanah \& Smyke, 2008), but only rarely on adolescent groups (Allen, 2008; Lionetti, Pastore, \& Barone, 2015; Wallis \& Steele, 2001; Zegers, Schuengel, van IJzendoorn, \& Janssens, 2006, 2008). We therefore decided to contribute to the small set of attachment studies in clinically disturbed adolescents with an outpatient adolescent group.

In summary, our aim is to investigate whether attachment representations differentiate adolescents with CSA from those with clinical depression and from controls and whether information from AAIs complements the symptomatology derived from conventional 
psychiatric assessments for depression and post-traumatic stress. The following three hypotheses are examined.

(1) Adolescents with CSA will more often show an insecure and especially an unresolved-disorganized attachment representation than adolescents with clinical depression and non-clinical controls.

(2) Unresolved status and low coherence of mind will be associated with more severe clinical symptomatology in both clinical adolescent groups.

(3) Unresolved status and coherence of mind will differentiate the CSA group from the clinical depression group and controls beyond psychiatric symptomatology.

\section{Methods \\ Participants}

AAI and clinical data were collected for two outpatient groups of adolescents and one control group: $N=21$ CSA adolescents, $N=28$ adolescents with DSM-IV anxiety or depressive disorders, further referred to as clinical depression (DEP) and $N=28$ matched non-clinical controls (CNTR). The adolescents from all three groups were part of the EPISCA study (Emotional Pathways' Imaging Study in Clinical Adolescents), a longitudinal study in which adolescents were followed over a six-month period. The CSA and DEP groups underwent a diagnostic assessment and an MRI scanning protocol before the start of their regular psychotherapy, and three and six months later. The controls were examined over similar periods (see for more detail van den Bulk et al., 2013). The current study reports on the AAI and clinical characteristics of the three groups using data of the first measurement only. The imaging data will be published in separate reports.

Related to the neuroimaging protocol all participants met the following inclusion criteria: aged between 12 and 20 years, estimated full scale IQ $\geq 80$ as measured by Dutch versions of the Wechsler Intelligence Scales for Children (WISC-III; Wechsler, 1991) or Adults (WAIS-III; Wechsler, 1997), being right-handed, normal or corrected-tonormal vision, sufficient understanding of the Dutch language, no history of neurological impairments and no contraindications for MRI testing (e.g. braces, metal implants, lead tattoos, irremovable piercings, claustrophobia or possible pregnancy). The CSA group was recruited in two psychotrauma centres of child and adolescent psychiatric institutes in the Leiden region in the Netherlands. Inclusion criteria for the CSA group were having experienced sexual abuse during their lifetime more than once by one or more perpetrators in- or outside the family, and being referred for treatment at the psychotrauma centre. The inclusion criteria for the DEP group were: being referred for outpatient treatment, having a clinical diagnosis of DSM-IV depressive and/or anxiety disorders and no history of CSA (see Aghajani et al., 2013; Pannekoek et al., 2014a, 2014b). Exclusion criteria for both clinical groups were: (1) a primary DSM-IV diagnosis of Attention Deficit and Hyperactivity Disorder, Oppositional Defiant Disorder, Conduct Disorder, Pervasive Developmental Disorders, Tourette's syndrome, Obsessive-Compulsive Disorder, bipolar disorder, and psychotic disorders; (2) current use of psychotropic medication other than stable use of SSRI's or amphetamine medication on the day of the scanning; and (3) current substance abuse. The controls were recruited through local advertisement, with the following inclusion criteria: no clinical scores on validated mood and behavioural 
questionnaires or past or current DSM-IV classification, no history of traumatic experiences and no current psychotherapeutic intervention of any kind.

To objectify any abuse or neglect as well as risk for functional impairment and morbidity (Karam et al., 2014), we verified police reports, involvement of child welfare, and family custody or other child protection measures as to have an estimate of the severity and impact of problems. Most adolescents with CSA (87\%) reported during the AAI serious and/or longstanding physical sexual contact including repeated or group rape, in $63.6 \%$ by a person other than an attachment figure. In addition, $36.4 \%$ of the CSA group also experienced physical abuse, $22.7 \%$ by a person other than an attachment figure, $9.1 \%$ by an attachment figure, in one case by both. Sexual abuse was reported to the police in $60.9 \%$, child welfare was involved in $56.5 \%$ of the cases, while $17.4 \%$ had a child protection measure (family custody). None of the participating control and DEP adolescents had experienced CSA, but they did mention physical and emotional abuse, bullying, and other incidents. No controls were involved with police, child welfare or child protection, while $23 \%$ of the DEP group had child welfare involvement.

From the original sample of 82 adolescents, three participants were excluded due to technical problems, i.e. failed voice and video recording (one CSA), unintelligible recording (one control), incorrect interview technique (one control). Two participants (one control and one DEP) were excluded because they refused the AAI because of the interview itself. Of the $N=77$ in this sample, $86 \%$ were girls. All CSA adolescents fulfilled the DSM-IV criteria for PTSD, according to the ADIS, however one adolescent missed a point on the interference score to fully qualify for PTSD. SSRI's were used by four of the CSA group and two of the DEP group.

Written informed assent and consent was obtained from all adolescents and their parents. Participants received a financial compensation including travel expenses. The medical ethics committee of the Leiden University Medical Centre approved the study.

\section{Procedure}

After adolescents and their parents had given assent and consent to participate in the EPISCA study they filled out questionnaires, usually at home, and were tested for IQ and interviewed for DSM-IV classification and attachment representation at the clinic in separate appointments.

\section{Measures}

We used the following measures: the AAI (attachment representations), the ADIS C/P (DSM-IV classifications), WISC/WAIS (intelligence), TSCC, A-DES, CDI (clinical symptoms of trauma, dissociation respectively depression), PDS (puberty development), and ZALC (socio-emotional development).

AAI: Adult Attachment Interview (Main et al., 1985) is an hour-long semi-structured interview (Hesse, 2008), validated for adolescents (Beijersbergen, Bakermans-Kranenburg, van IJzendoorn, \& Juffer, 2008; Beijersbergen, Juffer, Bakermans-Kranenburg, \& van IJzendoorn, 2012) and with additional trauma probes (Madigan, Vaillancourt, McKibbon, \& Benoit, 2012). The AAI asks how the interviewee thinks about the relationship with parents or other primary caregivers in his or her youth, how these experiences have influenced him or her, how the actual relationship with parents or other primary caregivers is and whether there were any experiences of illness, separation, fear, trauma or loss. The 
interviewee is asked to give specific examples supporting each evaluation. The coherence of the narrative matters, not its autobiographical content.

After transcription and coding of the AAI according to the manual of Main et al. (2003) by a certified coder, an attachment representation classification can be given according to the DEFU system: dismissive (Ds), preoccupied (E), secure-autonomous (F), unresolved-disorganized (Ud). Ds, E and F classifications are organized forms of attachment (Hesse, 2008; Main, 2000), while Ud represents disorganized forms of attachment. In organized attachment representations there is one coherent mental strategy with regard to attachment figures, either secure-autonomous (F) or insecure (Ds or E). In disorganized attachment representation different mental strategies with regard to attachment figures are used simultaneously or sequentially, often contradictory (Hesse \& Main, 2000). In insecure-dismissive attachment representations (Ds) the narrative is coloured by idealization, denial and lack of memory, resulting in moderate to low coherence of the narrative. In insecure-preoccupied representations (E) the narrative is coloured by vague and passive speech or speech showing signs of preoccupied anger or fear, also resulting in moderate to low coherence of narrative. A high to moderate coherence of the narrative is seen in secure-autonomous $(\mathrm{F})$ attachment interviews in which the interviewee can give ample evidence for general evaluative statements made regarding attachment relationships and attachment experiences whether good or bad.

In case of unresolved loss or trauma, the attachment representation is labelled unresolved-disorganized (Ud). This classification can be given in addition to a Ds, E or F classification. A fifth category, cannot classify (CC), has been suggested by Hesse (1999) and is used when the interviewee presents contrasting attachment strategies for attachment figures in the course of the interview resulting in very low coherence of narrative. The CC classification can be given in combination with any DEFU classification and renders the final classification disorganized. Besides the five categories Ds, F, E, U, and CC, we used the dichotomous variables F-nonF and Ud-nonUd. Derived from the DEF system, the contrast between F-nonF is considered a forced two-way classification in which unresolved state of mind is not taken into account. This implies that subjects with a secure and at the same time unresolved state of mind are considered secure, just like subjects who were classified as secure-autonomous without the additional classification as unresolved. The contrast between Ud-nonUd is used to characterize the presence or absence of unresolved-disorganized attachment representations ( $U$ or $C C$ ). Coherence of mind and Unresolved for loss or trauma (Ulosstrauma) are two dimensional scales of the AAI which are assigned scores rated between 1 and 9 by the judge coding the AAI. Lowest score for Coherence means there is little or no coherence of mind, highest score for Ulosstrauma means there is high impact of loss or trauma. A $\log _{10}$ transformation was performed to lift the positive skew for Ulosstrauma. To avoid multiple testing in a relatively small sample we decided a priori to focus in our analyses on these two central AAI scales that cover most of the variance between the classifications in clinical samples.

Because of the recruitment procedure the dominant factor in the $U$ classification and scale score was trauma, and in only one case was loss rated higher than trauma which resulted in a $U$ classification based on loss but accompanied with traumatic experiences as well. In our relatively small sample it was therefore impossible to separate Uloss and Utrauma. We refrained from a cumulative loss and trauma experiences score, because we were aware of the measurement problems inherent in reconstructing past (loss or trauma) experiences especially in case of high co-morbidity. This is why we decided to stick to the AAI representational variables not suffering from the retrospective bias (van IJzendoorn, 1995b) 
The AAI is found to have remarkably good test-retest, discriminant reliability as well as predictive validity (Aikins, Howes, \& Hamilton, 2009; Bakermans-Kranenburg \& van IJzendoorn, 1993, 2009; Benoit \& Parker, 1994; Crowell et al., 1996; Sagi et al., 1994; Steele, Steele, \& Fonagy, 1996; van IJzendoorn, 1995a; Waters et al., 2000). In this study, the AAI was administered by $\mathrm{MJvH}$ and CIG, verbatim transcribed according to protocol, and coded by GK (trained by Diane and Dave Pederson), and SdH (trained by Diane and Dave Pederson, and June Sroufe). Both reached intercoder reliability standards in the AAI classification system. Ten cases were also coded by MJBK. Interrater agreement in this sample was $80 \%$ for F-nonF, $90 \%$ for Ud-nonUd and $70 \%$ for four-way classification (DEFU). Kappas for coding F-nonF (.59) and Ud-nonUd (.62) were both statistically significant and reasonable to satisfactory.

ADIS: The Anxiety Disorders Interview Schedule Child and Parent Versions (ADIS C/ P) (Silverman, Saavedra, \& Pina, 2001; Dutch version by Siebelink \& Treffers, 2001a, 2001b) are semi-structured interviews designed specifically for DSM-IV classification of anxiety and other related disorders such as depression and PTSD in children and adolescents. Based on results obtained from the interviews with the children and parents separately, the interviewer provides definite classifications. The ADIS is used in many studies to describe the participants' DSM-IV classifications in clinical and maltreated adolescents (e.g. Brown, DiNardo, Lehman, \& Campbell, 2001). With regard to the psychometric qualities, Silverman and colleagues (2001) reported excellent validity and reliability. In this study, the ADIS was applied to all participants by certified trained clinicians and researchers.

WISC-III-NL and WAIS-III: Short versions of the Wechsler Intelligence Scale for Dutch Children aged 6-16 years, WISC-III-NL (Wechsler, 1991) and adolescents aged 16 and above and adults, the Wechsler Adult Intelligence Scale, WAIS-III (Wechsler, 1997) were used. They consisted of six subtests: picture completion, similarities, picture arrangement, arithmetic, block design, and comprehension. In earlier studies, these subtests were found to give a valid and reliable IQ estimate (reliability coefficient > .90; e.g. Crawford, Mychalkiw, Johnson, \& Moore, 1996; Kaufman, Kaufman, Balgopal, \& McLean, 1996).

TSCC: The Trauma Symptom Checklist for Children (Briere, 1996) is a 54-item selfreport for children and adolescents aged 8-17, which measures trauma-related symptoms. There are separate profile sheets for boys and girls. On a 4-point scale (never to almost all of the time), the adolescent indicates how often a thought, feeling or behaviour occurs. The items are grouped into six clinical scales on anxiety, depression, post-traumatic stress, sexual concerns, dissociation, and anger. The total score is summed from the frequency of all items, with scores ranging from 0 to 162 . The total score reflects post-traumatic symptomatology (Wekerle et al., 2001). The standardization of TSCC was based on 3008 school children from different parts of the USA. Good psychometric qualities have repeatedly been confirmed in other studies on trauma in adolescents (Nilsson, Wadsby, \& Svedin, 2008). In the present study, only the TSCC total score was used (Cronbach's alpha coefficient .96).

A-DES: The Adolescent Dissociative Experiences Scale (Armstrong, Putnam, Carlson, Libero, \& Smith, 1997) is a self-report for adolescents aged 11-18 measuring possible dissociation. The self-report consists of 30 questions reflecting experiences and coping skills rather than symptoms and disabilities. It consists of four different scales: (1) dissociative amnesia; (2) absorption and imaginative involvement; (3) passive influence; and (4) depersonalisation and derealisation, items reflecting dissociated identity and dissociated relatedness. All items are scores from 0 (never the case) to 10 (always the case). The total score is the mean of all item scores (range $0-10$ ). A mean score of $\geq 4.0$ 
suggests pathological dissociation, while a mean score of 3 suggests high risk for dissociative disorder (Armstrong et al., 1997). Smith and Carlson (1996) and Armstrong and colleagues (1997) found that the A-DES had good validity and reliability. In this study the mean total score on the A-DES was used, and had a Cronbach's alpha coefficient of .95 . A $\log _{10}$ transformation was performed to lift the positive skew.

CDI: The Children's Depression Inventory (Kovačs, 1985) is a 27-item, self-rated, depression symptoms-oriented scale suitable for youths aged 7 to 17 . The CDI is sensitive to changes in depressive symptoms over time and is a useful index of the severity of the depression. There are five subscales that measure different components of depression: (1) anhedonia; (2) negative self-esteem; (3) ineffectiveness; (4) interpersonal problems; and (5) negative mood. Each item offers respondents three alternatives scored 0 (absence of symptom), 1 (mild symptom), or 2 (clearly present symptom) and accordingly raw scores range from 0 to 54. Several studies (e.g. Matthey \& Petrovski, 2002) recommended 13 as a cut-off score for clinical populations and 19 as the threshold for community samples in the United States, while 16 has been recommended as a cut-off for Dutch samples (e.g. Roelofs et al., 2010). The CDI has good psychometric properties of validity and reliability (Kovačs, 1992), though discriminant validity has been subject to discussion (e.g. Timbremont, Braet, \& Dreessen, 2004). In this study the total CDI score is used and has a Cronbach's alpha coefficient of .93.

PDS: The Pubertal Development Scale (Petersen, Crockett, Richards, \& Boxer, 1988) measures the actual level of physical development during puberty. It is a 5-item self-report that measures items like body growth, body hair, and skin changes for both sexes. For boys there are items on beard growth and voice changes. For girls there are items on breast growth and menstrual bleeding. Items can be answered on a 5-point scale with a total score range of 0-20. Internal consistency is adequate for both sexes, consistent across samples, while the predictive validity of the PDS is satisfactory (Robertson et al., 1992). The PDS was filled out by $87 \%$ of participants in this study.

ZALC: The Sentence Completion Test for Children and Youth (Westenberg, 2002) measures the socio-emotional level of development. It is an 80 item questionnaire containing incomplete sentences that have to be completed by the child or youngster. It is based on the Washington University Sentence Completion Test (WUSCT), a test developed by Loevinger (Loevinger, 1976; Westenberg, Jonckheer, Treffers, \& Drewes, 1998), who views psychosocial development as changes in impulse control, conscious preoccupations, character development and interpersonal orientation. There is evidence for good reliability and discriminant validity (Drewes \& Westenberg, 2001). The ZALC was filled out by $91 \%$ of participants in this study.

\section{Analysis}

Preliminary descriptive analyses were performed and distribution of data was checked. A MANOVA for diagnostic group differences regarding IQ and age was performed, as well as crosstabs for differences in PDS and ZALC categories with Pearson's $\chi^{2}$ and Cramer's $V$ reported. Bootstraps (1000 samples) were performed in order to acquire robust standard errors in the relatively small study group. Fisher's exact test (2-sided) was reported in case of bootstrap. A MANOVA was performed on total scale scores of the psychiatric symptoms measures TSCC, A-DES and CDI. Subsequent MANCOVA's were performed with age and IQ as covariates, because groups differed significantly in this respect. Posthoc LSD tests (alpha 0.05) were performed to examine univariate effects. Effect sizes 
(partial $\eta^{2}$ ) were reported; interpretation of these effect sizes is debatable, rule of thumb might be: $.02 \sim$ small, $.13 \sim$ medium $.26 \sim$ large.

To test the first hypothesis group differences in attachment representations were examined, using categorical and dimensional AAI variables. For the categorical approach the fiveway classification DEFCCU was used, unless explicitly stated otherwise. We used adjusted residuals to determine over- or under-representation of attachment classifications. Also the dichotomies F-nonF and Ud-nonUd were used. For the dimensional approach we used two continuous state of mind scales of the AAI, Coherence and Ulosstrauma, as dependent variables, group as independent variable with age and IQ as covariates in a MANCOVA.

To test the second hypothesis, Pearson correlation was used to examine the associations between the AAI Coherence and Ulosstrauma scale scores and the psychiatric symptoms measures TSCC, A-DES and CDI total scale scores.

To examine the third hypothesis, we tested whether the AAI could distinguish diagnostic groups beyond psychiatric symptom profile using dimensional attachment scales (Ulosstrauma and Coherence). We performed MANCOVA's on groups with Ulosstrauma and Coherence as dependent variables and TSCC, A-DES and CDI as covariates.

\section{Results}

\section{Sample characteristics}

The groups differed with respect to age $\left(F_{(2,74)}=4.68, p<.01\right.$, partial $\left.\eta^{2}=.11\right)$ and IQ $\left(F_{(2,74)}=4.49, p<.01\right.$, partial $\left.\eta^{2}=.11\right)$, with CSA and DEP groups being significantly older than the controls (both $p<.05$ ), and the CSA group having a significantly lower IQ than both the DEP and controls (both $p<.05$ ). As expected based on group differences for age, the PDS showed that the CSA and DEP groups were most often in the late- or post-pubertal phase, while the controls were most often in the mid- or late-pubertal phase (Pearson's $\chi_{(8)}^{2}=22.14$, exact $p=.00$, Cramer's $V=.41)$. Surprisingly, socio-emotional development as measured with the ZALC was equal across groups (Pearson's $\chi_{(12)}^{2}=10.36$, exact $p=.64$, Cramer's $V=.27$ ), with most adolescents (44/70) being rated as conformists. Despite the older age of the clinical groups, they were not more often self-aware or responsible than controls, but in contrast functioning at the same socio-emotional developmental level.

\section{Psychiatric symptoms profile}

On the psychiatric symptoms measures, a MANCOVA with age and IQ as covariates showed a significant effect for group with rather large effect sizes $\left(F_{(10,120)}=7.48\right.$, $p<.00$, partial $\eta^{2}=.38$ ). As expected, the two clinical groups differed from the controls on all three scale scores, but not among each other (TSCC and CDI both at $p<.00$; A-DES CNTR vs. DEP group at $p=.04$ and CNTR vs. CSA group at $p=.00 ;$ TSCC $F$ $(2,65)=12.02, p<.00$, partial $\eta^{2}=.28 ;$ A-DES $F_{(2,65)}=4.73, p=.01$, partial $\eta^{2}=.13$; CDI $F_{(2,65)}=23.40, p<.00$, partial $\eta^{2}=.43$; see Table 1$)$.

\section{AAI profile}

Regarding the most fine-grained DEFCCU attachment classifications cross-tabulation with group resulted in a Fisher's Exact Test of 18.39, $p=.00$. Inspection of the adjusted standardized residuals showed that the CC classification differentiated the CSA group 


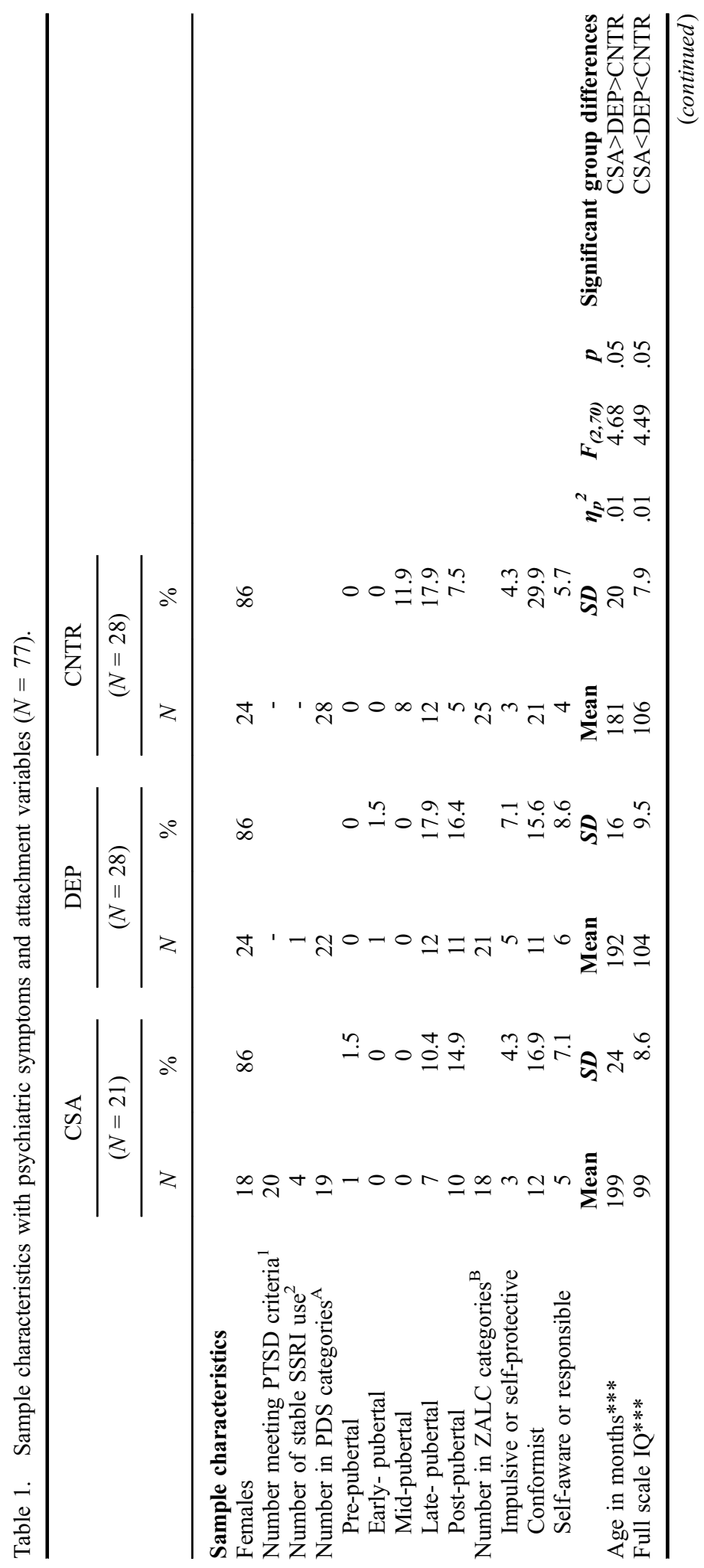




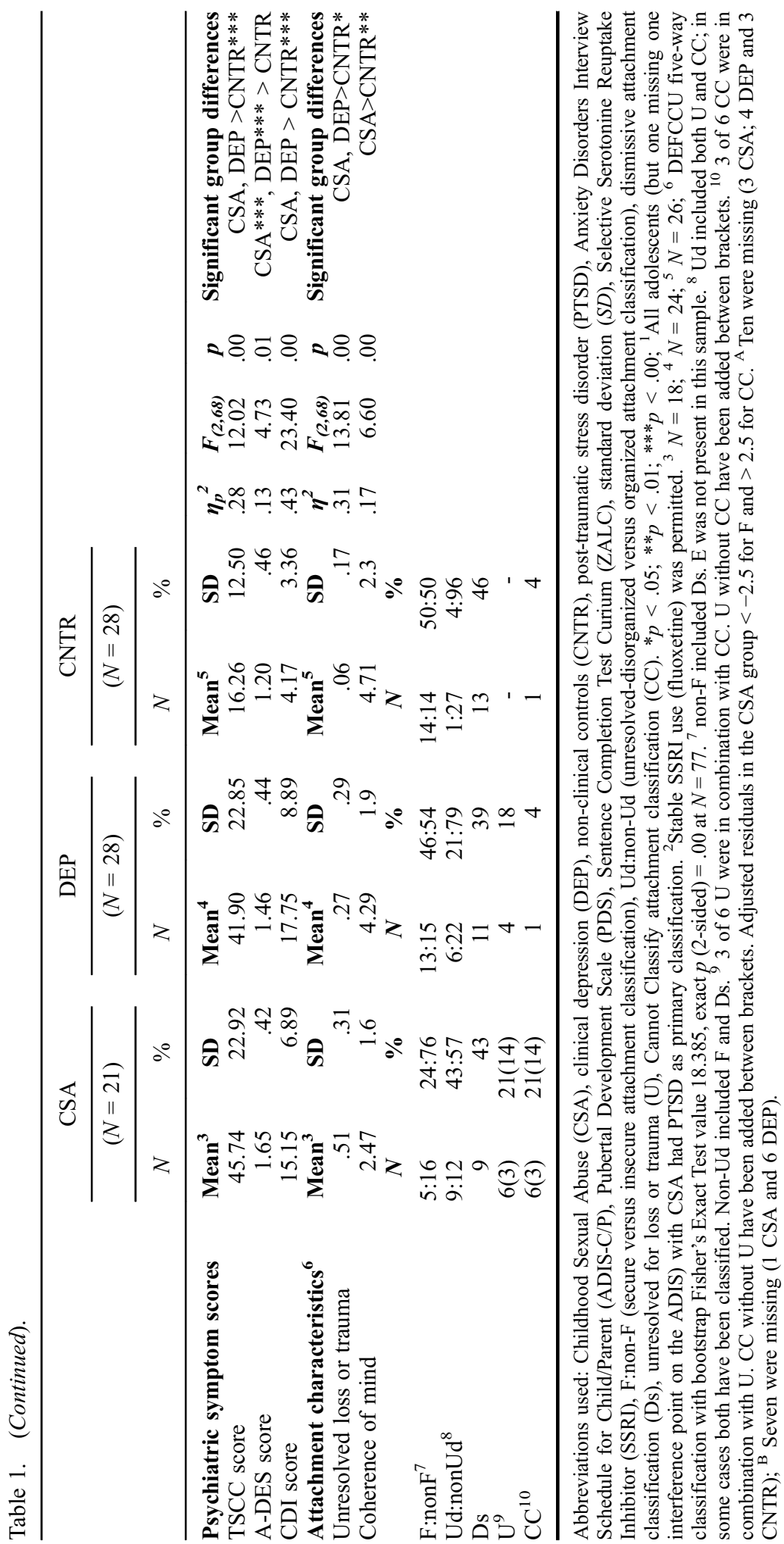


(adjusted residual 3.2) from both the DEP (adjusted residual -1.5) and the CNTR groups (adjusted residual-1.5). As can be seen in Table 1, most of the adolescents in the CSA group had insecure attachments (16/21: 76\%), and the same was true for about half of the adolescents in the two other groups. The percentage with dismissing classification was similar in the three groups (CSA 43\% (9/21), DEP 39\% (11/28), 46\% (13/28)). None of the adolescents had a preoccupied (E) classification. Unresolved-disorganized representations including CC were significantly more present in the CSA group (9/21: $43 \%$; adjusted residual 2.9) than in the DEP group (6/28: 21\%; adjusted residual 0.1$)$ and controls (1/28: 4\%; adjusted residual -2.8). In addition, the dimensional AAI scale scores Ulosstrauma and Coherence differentiated the three groups, with age and IQ included as covariates $\left(F_{(10,120)}=7.48, p<.00\right.$, partial $\left.\eta^{2}=.38\right)$. Post hoc LSD analysis showed that the CSA group had a significantly higher score than the controls and DEP group on the Ulosstrauma scale $\left(F_{(2,65)}=13.81, p<.00\right.$, partial $\left.\eta^{2}=.31\right)$, and a significantly lower score than the controls and DEP group on the Coherence scale $\left(F_{(2,65)}=6.60, p=.00\right.$, partial $\eta^{2}=.17$; see Table 1 ).

\section{Associations between AAI scales and psychiatric symptoms}

The Ulosstrauma and Coherence variables correlated negatively with each other $(r=-.35$; $p<.01$ ), meaning that higher Ulosstrauma scores were associated with a lower Coherence score. The Ulosstrauma scale score correlated positively with total scores on the TSCC (Pearson's $r=.34, p<.00$ ) and CDI (Pearson's $r=.27, p<.05$ ), but not with the total A-DES score. In contrast, there were no significant associations between the Coherence scores and the total TSCC, A-DES and CDI scores. The scores on TSCC, A-DES and CDI correlated positively and significantly with each other (Pearson's $r=.56-.76$, all $p$ s $<.01$, see Table 2).

\section{AAI scales differentiate CSA from both clinical depression and controls}

When examining group differences for Ulosstrauma and Coherence, while controlling for age, IQ and psychiatric symptoms measured by TSCC, A-DES, and CDI, a significant main effect of group was found $\left(F_{(4,120)}=5.70, p<.00\right.$, partial $\eta^{2}=.17$; Coherence $F_{(2,60)}=6.45$,

Table 2. Pearson correlations $(r)$ between the two AAI scales "Coherence of Mind" and "Unresolved" and clinical characteristics ${ }^{1}(N=68)$.

\begin{tabular}{lccccc}
\hline & $\begin{array}{c}\text { Unresolved for loss } \\
\text { or trauma }\end{array}$ & $\begin{array}{c}\text { Coherence of } \\
\text { mind }\end{array}$ & TSCC & A-DES & CDI \\
\hline $\begin{array}{l}\text { Unresolved for loss or } \\
\text { trauma }\end{array}$ & $-.35^{* *}$ & $.34^{* *}$ & $.21^{2}$ & $27^{*}$ \\
$\begin{array}{l}\text { Coherence of mind } \\
\text { TSCC }\end{array}$ & & -.09 & -.17 & -.09 \\
A-DES & & & $.63^{* * *}$ & $.76^{* * *}$ \\
CDI & & & & & $.56^{* * *}$ \\
\hline
\end{tabular}

Abbreviations used: Trauma Symptom Checklist (TSCC), Adolescent version Dissociative Experiences Scale (ADES), Child Depression Inventory (CDI). *Significant at $p<.05, * * p<.01, * * * p<.00,{ }^{2}(p=.09)$. ${ }^{1}$ Because questionnaires were not filled out by three CSA adolescents (TSCC, A-DES, CDI), and by four (A-DES), three (TSCC) and one (CDI) depressed adolescents, the analyses were performed on $N=68$. Note: Because less than $20 \%$ of the items in TSCC, ADES and CDI were missing, expectation maximization as regression method was used to calculate the scale scores. 
$p=.00$, partial $\eta^{2}=.18$; Ulosstrauma $F_{(2,60)}=10.63, p<.00$, partial $\left.\eta^{2}=.26\right)$. Post-hoc LSD analyses indicated that the CSA group had a significantly higher score on the Ulosstrauma scale $(p<.02)$ and a significantly lower score on the Coherence scale $(p<.01)$ compared to both DEP group and controls. DEP group and controls had equal Coherence scale scores $(p=.21)$.

\section{Discussion}

In the current study we tested whether attachment representation as measured with the AAI can distinguish a CSA group from a clinically depressed and a non-clinical control group when taking psychiatric symptoms into account. First, we found that the CSA group was most disorganized according to the AAI classifications, compared to both the clinical depression and control groups. This was due to the overrepresentation of unresolved trauma and "Cannot Classify" classifications (U/CC). Secondly, unresolved status but not coherence of mind correlated with severity of clinical symptomatology. Third, the CSA group had the highest score of being unresolved and the lowest coherence of mind score, compared to the clinical depression group and the controls. Co-varying IQ, age and psychiatric symptoms, only coherence of mind uniquely differentiated the CSA group from both the clinical depression group and controls. The unresolved loss or trauma scale differentiated both clinical groups from the controls, whereas coherence of mind differentiated CSA from the clinical depression and control groups.

It should be noted that the current sample showed rather elevated levels of psychiatric symptomatology, with serious problems requiring intensive outpatient treatment. For example, all adolescents but one in the CSA group had PTSD according to the ADIS and scores for post-traumatic stress, dissociative and depressive symptoms were rather high in both clinical groups. In addition, we found a very high percentage of serious and/ or longstanding physical sexual contact including repeated or group rape and implicit emotional abuse and neglect in the CSA group, and a high percentage of physical abuse, losses, bullying and other traumatic incidents in both clinical groups. All of these results together imply that a substantial percentage of adolescents with CSA seeking professional help suffer from complex PTSD (Herman, 1992; Jonkman, Verlinden, Bolle, Boer, \& Lindauer, 2013; Karam et al., 2014) or "PTSD with prominent dissociative symptoms" (DSM-5; American Psychiatric Association [APA], 2013). The severity of the experiences and symptoms might be one of the reasons why their unresolved status and low coherence of mind, classified as unresolved-disorganized attachment representations (with an overrepresentation of CC classifications), characterize them even beyond regular psychiatric symptomatology.

The current study extends our knowledge by suggesting that adolescents with CSA can be characterized by a higher frequency of unresolved-disorganized attachment representations in contrast to clinically depressed adolescents as well as to typically developing adolescents who showed an overrepresentation of dismissive attachment representations. Our finding is in line with results found in traumatized adults (Cassidy \& Mohr, 2001; Liotti, 2004; Lyons-Ruth et al., 2006), and in an at-risk sample of adolescent mothers with complex trauma symptoms, who showed elevated levels of unresolved attachments (Neufeld Bailey et al., 2007). Because of the cross-sectional nature of our study, it is not clear whether adolescents with CSA have unresolved-disorganized attachment representations as a consequence of CSA or whether they were more vulnerable for CSA due to an already present insecure or unresolveddisorganized attachment representation (Harari et al., 2009; Liotti, 2004). This remains to be investigated in longitudinal studies. 
Attachment was examined using categorical as well as dimensional variables of the AAI. We used both strategies because the conventional coding system (Main et al., 2003) yields categorical classifications as well as continuous scales, and because including dimensional scales may imply more statistical power to identify theoretically anticipated correlates of insecure states of mind than the classifications. It should be noted that if we would have only relied on the continuous scales the strong association between the CC classification and CSA would have escaped our attention. If we would only have concentrated on the classifications we might not have observed the special role of coherence of mind in separating CSA from both the clinical depression group and the controls whereas the unresolved scale was not able to differentiate the CSA from the depression group, when we co-varied IQ, age, and psychiatric symptoms. The current debate about continuous versus categorical AAI measures seems most pertinent to typically developing adolescents with low levels of loss or trauma experiences and concomitant $\mathrm{U}$ and CC classifications (see for the debate: Roisman, Fraley, \& BoothLaForce, 2014; van IJzendoorn \& Bakermans-Kranenburg, 2014).

With regard to the association between representational attachment scales for coherence and unresolved on the one hand and psychiatric symptoms on the other hand, we only found that being unresolved correlated with self-reported post-traumatic and depressive symptoms, but not dissociative symptoms. There was no association between coherence of mind and psychiatric symptoms. Though the A-DES is shown to have good reliability and validity (Armstrong et al., 1997), like the adult version (Bernstein \& Putnam, 1986; van IJzendoorn \& Schuengel, 1996), dissociative symptoms may be easier to recognize for an interviewer or observer than for the dissociative adolescent herself. Furthermore, retrospect reporting may become distorted (Merckelbach \& Muris, 2001). For these reasons self-reported incidence of dissociation may be different from observed incidence and more than one informant in a multi-informant approach may be preferable to self-report only (van IJzendoorn \& Schuengel, 1996). Coherence of mind is an evaluative judgment on the narrative of the AAI and is independent of self-knowledge and conscious self-reports of the individual. Therefore it may be no surprise that coherence of mind and presence of psychiatric symptoms do not have strong associations.

Finally, by broadening insights in the interrelatedness of trauma, dissociation and disorganized attachment representation, this study adds evidence to theories addressing ways in which individuals (fail to) cope with traumatic experiences (Cassidy \& Mohr, 2001; Hesse, 2008; Liotti, 2004; Lyons-Ruth et al., 1999, 2006). These authors mentioned lapses in behavioural and attentional strategies in traumatized young adults having disorganized attachment representations, and we indeed found disorganized attachments of the most severe kind (i.e. CC) in particular in the CSA group, which was also characterized as showing lowest levels of coherence of mind. Liotti (2004) developed the diathesis-stress model of trauma, dissociation and disorganized attachment as "three strands of a single braid" implying inherent vulnerability. Maybe pre-existent lack of coherence of the autobiographical narrative due to highly insensitive parenting might have prepared the way for elevated disorganization in the face of sexual abuse. Of course this speculative interpretation should be tested in a longitudinal study.

With regard to implications for child and adolescent clinical practice, our findings suggest that attachment coherence and unresolved loss or trauma are potentially important concepts to be taken into account in child psychiatric diagnostic assessment and treatment of specific groups such as individuals suffering from CSA or clinical depression (Kim, Blashfield, Tyrer, Hwang, \& Lee, 2014; Tarren-Sweeney, 2014; Tyrer, 2014). For general clinical application of the AAI, Steele and Steele (2008) already described several 
possibilities. One of them is that the AAI effectively engages the adolescent in reflection on the relationship with his or her parents, losses and traumatic experiences. In doing so, the AAI creates a bond between the adolescent and clinician, which makes it easier for the adolescent to trust the clinician and engage in therapy, which is important for those traumatized or depressed (e.g. Sheftall, Mathias, Furr, \& Dougherty, 2013). For diagnosis and treatment of CSA victims, our findings emphasise the importance of not only looking at signs of unresolved trauma, but also at more general indications of an incoherent autobiographical narrative. Of course these implications are speculative and a follow-up study is needed to test the prognostic value of our findings and to study the usefulness of attachment representations in clinical practice.

We recognize several limitations in this study. First, caution is needed concerning the generalizability of our results: (a) Due to participation in a time-consuming, multidisciplinary neuroimaging study, recruitment was restricted by many inclusion and exclusion criteria and therefore our sample was fairly small in size $(N=77)$. (b) The ethnicity and gender of our sample was restricted. We mainly recruited female Caucasian participants, only a few boys or adolescents from other ethnic groups (Bicanič, 2014; van IJzendoorn \& Sagi-Schwartz, 2008). Secondly, as we conducted a cross-sectional study, conclusions about cause and time aspects of the phenomena studied cannot be drawn. To be able to add further evidence to the discussion on interrelatedness of trauma, dissociation and disorganized attachment representation (Herman, 1992; Liotti, 2004) and to disentangle the long term impact of attachment and trauma on personality development (e.g. Fransson, Granqvist, Bohlin, \& Hagekull, 2013; Pascuzzo, Cyr, \& Moss, 2013), further longitudinal research is needed. Thirdly, we restricted our coding of the AAI to the established classifications and scales, although in clinical groups such as ours, with severe trauma and symptomatology, complementary coding such as $\mathrm{HH}$ would have been a fruitful addition.

In conclusion, our study is the first to present attachment representations and psychiatric symptom profiles of adolescents with CSA compared to clinically depressed adolescents and controls. We used categorical classifications as well as dimensional scales of the AAI, besides psychiatric diagnostic classifications and clinical dimensional measures of trauma, dissociation, and depression. The study is the first to show that there is not only clinical (Steele \& Steele, 2008), but also scientific evidence that the AAI diagnostically differentiates a CSA group from clinical depression and control groups.

\section{Acknowledgements}

We thank all students, mental health professionals and personnel from Psychotraumacenter and GGZ Kinderen en Jeugd Rivierduinen, Curium-LUMC and KJTC Haarlem, who facilitated or helped with patient selection and inclusion or who helped with transcription of the AAI. We especially thank C.I. Gelderblom and B.G. van den Bulk for assisting with recruitment, data collection and database management, and C.I.G. also with transcription of AAI's. G. Kuipers, S. den Hollander and M.J. Bakermans-Kranenburg we thank for AAI coding. M.J. van Hoof was generously sponsored by the Psychotraumacenter and GGZ Kinderen en Jeugd and WOP Rivierduinen, and the Hilly Roevers-Bonnet fonds of the Dutch Society of Female Doctors (VNVA). M.H. van IJzendoorn was supported by a SPINOZA award. Last but not least we thank participants and their parents for their trust and efforts without which this research could not have been done.

\section{Disclosure statement}

No potential conflict of interest was reported by the authors. 


\section{References}

Aghajani, M., Veer, I. M., van Lang, N. D. J., Meens, P. H. F., van den Bulk, B. G., Rombouts, S. A. R. B., ... van der Wee, N. J. (2013). Altered white-matter architecture in treatment-naïve adolescents with clinical depression. Psychological Medicine, 44, 2287-2298. doi:10.1017/ S0033291713003000

Agrawal, H. R., Gunderson, J., Holmes, B., \& Lyons-Ruth, K. (2004). Attachment studies with borderline patients: A review. Harvard Review of Psychiatry, 12(2), 94-104. doi:10.1080/ 10673220490447218

Aikins, J. W., Howes, C., \& Hamilton, C. (2009). Attachment stability and the emergence of unresolved representations during adolescence. Attachment \& Human Development, 11(5), 491-512. doi:10.1080/14616730903017019

Allen, J. P. (2008). The attachment system in adolescence. In J. Cassidy \& P. R. Shaver (Eds.), Handbook of attachment: Theory, research and clinical applications (2nd ed., pp. 419-435). New York, NY: The Guilford Press.

American Psychiatric Association (APA). (2013). Diagnostic and statistical manual of mental disorders (5th ed., pp. 5-25). Arlington, VA: American Psychiatric Publishing.

Anda, R. F., Felitti, V. J., Bremner, J. D., Walker, J. D., Whitfield, C., Perry, B. D., ... Giles, W. H. (2006). The enduring effects of abuse and related adverse experiences in childhood. A convergence of evidence from neurobiology and epidemiology. European Archives of Psychiatry and Clinical Neuroscience, 256, 174-186. doi:10.1007/s00406-005-0624-4

Armstrong, J. G., Putnam, F. W., Carlson, E. B., Libero, D. Z., \& Smith, S. R. (1997). Development and validation of a measure of adolescent dissociation: The adolescent dissociative experiences scale. The Journal of Nervous \& Mental Disease, 185(8), 491-497. doi:10.1097/00005053199708000-00003

Bakermans-Kranenburg, M. J., \& van IJzendoorn, M. H. (1993). A psychometric study of the Adult Attachment Interview: Reliability and discriminant validity. Developmental Psychology, 29, 870-879. doi:10.1037/0012-1649.29.5.870

Bakermans-Kranenburg, M. J., \& van IJzendoorn, M. H. (2009). The first 10,000 Adult Attachment Interviews: Distributions of adult attachment representations in clinical and non-clinical groups. Attachment \& Human Development, 11(3), 223-263. doi:10.1080/14616730902814762

Barone, L., Fossati, A., \& Guiducci, V. (2011). Attachment mental states and inferred pathways of development in borderline personality disorder: A study using the Adult Attachment Interview. Attachment \& Human Development, 13(5), 451-469. doi:10.1080/14616734.2011.602245

Beijersbergen, M. D., Bakermans-Kranenburg, M. J., van IJzendoorn, M. H., \& Juffer, F. (2008). Stress regulation in adolescents: Physiological reactivity during the Adult Attachment Interview and conflict interaction. Child Development, 79(6), 1707-1720. doi:10.1111/cdev.2008.79.issue-6

Beijersbergen, M. D., Juffer, F., Bakermans-Kranenburg, M. J., \& van IJzendoorn, M. H. (2012). Remaining or becoming secure: Parental sensitive support predicts attachment continuity from infancy to adolescence in a longitudinal adoption study. Developmental Psychology, 48(5), 1277-1282. doi:10.1037/a0027442

Benoit, D., \& Parker, K. C. H. (1994). Stability and transmission of attachment across three generations. Child Development, 65, 1444-1457.

Bentovim, A., Cox, A., Bingley Miller, L., \& Pizzey, S. (2009). Safeguarding children living with trauma and family violence. Evidence-based assessment, analysis and planning interventions. London: Jessica Kingsley Publishers.

Bernstein, E. M., \& Putnam, F. W. (1986). Development, reliability, and validity of a dissociation scale. The Journal of Nervous and Mental Disease, 174(12), 727-735. doi:10.1097/00005053198612000-00004

Bersani, G., Moscariello, M. A., Bersani, F. S., Colletti, C., Anastasia, A., Prinzivalli, E., ... Salviati, M. (2014). Dissociative symptoms in female patients with mood and anxiety disorders: A psychopathological and temperamental investigation. European Review for Medical and Pharmacological Sciences, 18, 3217-3222.

Bicanič, I. A. E. (2014). Psychobiological correlates of rape in female adolescents (Dissertation). Ipskamp Drukkers b.v., Enschede.

Blakemore, S.-J. (2012). Imaging brain development: The adolescent brain. Neuroimage, 61, 397-406. doi:10.1016/j.neuroimage.2011.11.080

Briere, J. (1996). Trauma Symptom Checklist for Children (TSCC) professional manual. Odessa, FL: Psychological Assessment Resources. 
Brown, T. A., DiNardo, P. A., Lehman, C. L., \& Campbell, L. A. (2001). Reliability of DSM-IV anxiety and mood disorders: Implications for the classification of emotional disorders. Journal of Abnormal Psychology, 110(1), 49-58.

Caspi, A., McClay, J., Moffitt, T. E., Mill, J., Martin, J., Craig, I. W., ... Poulton, R. (2002). Role of genotype in the cycle of violence in maltreated children. Science, 297, 851-854. doi:10.1126/ science. 1072290

Cassidy, J., \& Mohr, J. J. (2001). Unsolvable fear, trauma, and psychopathology: Theory, research, and clinica. Clinical Psychology: Science and Practice, 8(3), 275-298.

Christiansen, D. M., \& Hansen, M. (2015, January). Accounting for sex differences in PTSD: A multi- variable mediation model. European Journal of Psychotraumatology, 19(6), 26068. doi:10.3402/ejpt.v6.26068. eCollection 2015.

Cicchetti, D., \& Toth, S. L. (1995). A developmental psychopathology perspective on child abuse and neglect. Journal of the American Academy of Child \& Adolescent Psychiatry, 34(5), 541-565. doi:10.1097/00004583-199505000-00008

Cloitre, M., Stolbach, B. C., Herman, J. L., van der Kolk, B., Pynoos, R., Wang, J., \& Petkova, E. (2009). A developmental approach to complex PTSD: Childhood and adult cumulative trauma as predictors of symptom complexity. Journal of Traumatic Stress, 22(5), 399-408. doi:10.1002/jts.20444

Committee on Professional Practice and Standards, APA Board of Professional Affairs. (2013). Guidelines for psychological evaluations in child protection matters. The American Psychologist, 68(1), 20-31. doi:10.1037/a0029891

Crawford, J. R., Mychalkiw, B., Johnson, D. A., \& Moore, J. W. (1996). WAIS-R short-forms: Criterion validity in healthy and clinical samples. British Journal of Clinical Psychology, 35, 638-640. doi:10.1111/bjc.1996.35.issue-4

Crowell, J. A., Waters, E., Treboux, D., O'Connor, E., Colon-Downs, C., \& Feider, O. (1996). Discriminant validity of the Adult Attachment Interview. Child Development, 67, 2584-2599.

Dozier, M., Chase Stovall-McClough, K., \& Albus, K. E. (2008). Attachment and psychopathology in adulthood. In J. Cassidy \& P. R. Shaver (Eds.), Handbook of attachment: Theory, research and clinical applications (2nd ed., pp. 718-744). New York, NY: The Guilford Press.

Drewes, M. J., \& Westenberg, P. M. (2001). The impact of modified instructions on ego-level scores: A psychometric hazard or indication of optimal ego level? Journal of Personality Assessment, 76(2), 229-249. doi:10.1207/S15327752JPA7602_07

Duchesne, S., \& Ratelle, C. F. (2014). Attachment security to mothers and fathers and the developmental trajectories of depressive symptoms in adolescence: Which parent for which trajectory? Journal of Youth and Adolescence, 43, 641-654. doi:10.1007/s10964-013-0029-z

Fergusson, D. M., McLeod, G. F. H., \& Horwood, L. J. (2013). Childhood sexual abuse and adult developmental outcomes: Findings from a 30-year longitudinal study in New Zealand. Child Abuse \& Neglect, 37, 664-674. doi:10.1016/j.chiabu.2013.03.013

Fonagy, P., Leigh, T., Steele, M., Steele, H., Kennedy, R., Mattoon, G., ... Gerber, A. (1996). The relation of attachment status, psychiatric classification and response to psychotherapy. Journal of Consulting and Clinical Psychology, 64, 22-31. doi:10.1037/0022-006X.64.1.22

Fransson, M., Granqvist, P., Bohlin, G., \& Hagekull, B. (2013). Interlinkages between attachment and the Five-Factor Model of personality in middle childhood and young adulthood: A longitudinal approach. Attachment \& Human Development, 15(2), 219-239. doi:10.1080/ 14616734.2013.754985

Frigerio, A., Costantino, E., Ceppi, E., \& Barone, L. (2013). Adult Attachment Interviews of women from low-risk, poverty, and maltreatment risk samples: Comparisons between the hostile/helpless and traditional AAI coding systems. Attachment \& Human Development, 15(4), 424-442. doi:10.1080/14616734.2013.797266

Gospodarevskaya, E. (2013). Post-traumatic stress disorder and quality of life in sexually abused Australian children. Journal of Child Sexual Abuse, 22(3), 277-296. doi:10.1080/ 10538712.2013.743953

Harari, D., Bakermans-Kranenburg, M. J., de Kloet, C. S., Geuze, E., Vermetten, E., Westenberg, H. G. M., \& van IJzendoorn, M. H. (2009). Attachment representations in Dutch veterans with and without deployment-related PTSD. Attachment \& Human Development, 11(6), 515-536. doi: $10.1080 / 14616730903282480$

Herman, J. (1992). Trauma and recovery. New York, NY: Basic Books. 
Hesse, E. (1999). The Adult Attachment Interview: Historical and current perspectives. In J. Cassidy \& P. R. Shaver (Eds.), Handbook of Attachment: Theory, research and clinical applications (pp. 395-433). New York, NY: The Guilford Press.

Hesse, E. (2008). The Adult Attachment Interview: Protocol, method of analysis, and empirical studies. In J. Cassidy \& P. R. Shaver (Eds.), Handbook of attachment (pp. 552-598). New York, NY: The Guilford Press.

Hesse, E., \& Main, M. (2000). Disorganized infant, child, and adult attachment: Collapse in behavioral and attentional strategies. Journal of the American Psychoanalytic Association, 48 (4), 1097-1127, discussion 1175-1187. doi:10.1177/00030651000480041101

Jonkman, C. S., Verlinden, E., Bolle, E. A., Boer, F., \& Lindauer, R. J. L. (2013). Traumatic stress symptomatology after child maltreatment and single traumatic events: Different profiles. Journal of Traumatic Stress, 26, 225-232. doi:10.1002/jts.21792

Karam, E. G., Friedman, M. J., Hill, E. D., Kessler, R. C., McLaughlin, K. A., Petukhova, M., ... Koenen, K. C. (2014). Cumulative traumas and risk thresholds: 12-month PTSD in the world mental health (WMH) surveys. Depression and Anxiety, 31, 130-142.

Kaufman, A. S., Kaufman, J. C., Balgopal, R., \& McLean, J. E. (1996). Comparison of three WISCIII short forms: Weighing psychometric, clinical and practical factors. Journal of Clinical Child Psychology, 25(1), 97-105. doi:10.1207/s15374424jccp2501_11

Kim, Y.-R., Blashfield, R., Tyrer, P., Hwang, S.-T., \& Lee, H.-S. (2014). Field trial of a putative research algorithm for diagnosing ICD-11 personality disorders in psychiatric patients: 1 . Severity of personality disturbance. Personality and Mental Health, 8(1), 67-78. doi:10.1002/ pmh.v8.1

Kim-Spoon, J., Cicchetti, D., \& Rogosch, F. A. (2013). A longitudinal study of emotion regulation, emotion lability-negativity, and internalizing symptomatology in maltreated and non-maltreated children. Child Development, 84(2), 512-527. doi:10.1111/cdev.2013.84.issue-2

Kovačs, M. (1985). The Children's Depression Inventory (CDI). Psycho-pharmacology Bulletin, 21, 995-998.

Kovačs, M. (1992). Children's Depression Inventory (CDI) manual. New York, NY: Multi-Health Systems.

Levinson, A., \& Fonagy, P. (2004). Offending and attachment: The relationship between interpersonal awareness and offending in a prison population with psychiatric disorder. Canadian Journal of Psychoanalysis, 12(2), 225-251.

Lionetti, F., Pastore, M., \& Barone, L. (2015). Attachment in institutionalized children: A review and meta-analysis. Child Abuse \& Neglect, 42, 135-145. doi:10.1016/j.chiabu.2015.02.013

Liotti, G. (2004). Trauma, dissociation and disorganized attachment: Three strands of a single braid. Psychotherapy: Theory, Research, Practice, Training, 41, 472-486. doi:10.1037/00333204.41.4.472

Loevinger, J. (1976). Ego development: Conceptions and theories. San Francisco, CA: Jossey-Bass.

Lyons-Ruth, K. (2003). The two-person construction of defenses: Disorganized attachment strategies, unintegrated mental states, and hostile/helpless relational processes. Journal of Infant, Child, and Adolescent Psychotherapy, 2, 105-114.

Lyons-Ruth, K., Bronfman, E., \& Parsons, E. (1999). Chapter IV. Maternal frightened, frightening, or atypical behavior and disorganized infant attachment patterns. Monographs of the Society for Research in Child Development, 64(3), 67-96; discussion 213-20. doi:10.1111/15405834.00034

Lyons-Ruth, K., Brumariu, L. E., Bureau, J.-F., Hennighausen, K., \& Holmes, B. (2014). Role confusion and disorientation in young adult-parent interaction among individuals with borderline symptomatology. Journal of Personality Disorders, 28(165), 1-22. doi:10.1521/ pedi_2014_28_165

Lyons-Ruth, K., Bureau, J.-F., Holmes, B., Easterbrooks, A., \& Brooks, N. H. (2013). Borderline symptoms and suicidality/self-injury in late adolescence: Prospectively observed relationship correlates in infancy and childhood. Psychiatry Research, 206, 273-281. doi:10.1016/j. psychres.2012.09.030

Lyons-Ruth, K., Dutra, L., Schuder, M. R., \& Bianchi, I. (2006). From infant attachment disorganization to adult dissociation: Relational adaptations or traumatic experiences? Psychiatric Clinics of North America, 29(1), 63-86. doi:10.1016/j.psc.2005.10.011 
Lyons-Ruth, K., Melnick, S., Patrick, M., \& Hobson, R. P. (2007). A controlled study of hostilehelpless states of mind among borderline and dysthymic women. Attachment \& Human Development, 9(1), 1-16. doi:10.1080/14616730601151417

Lyons-Ruth, K., \& Spielman, E. (2004). Disorganized infant attachment strategies and helplessfearful profiles of parenting: Integrating attachment research with clinical intervention. Infant Mental Health Journal, 25(4), 318-335. doi:10.1002/(ISSN)1097-0355

Lyons-Ruth, K., Yellin, C., Melnick, S., \& Atwood, G. (2003). Childhood experiences of trauma and loss have different relations to maternal unresolved and Hostile-Helpless states of mind on the AAI. Attachment \& Human Development, 5(4), 330-352. doi:10.1080/ 14616730310001633410

MacKinnon, L. (2012). The neurosequential model of therapeutics: An interview with Bruce Perry. The Australian and New Zealand Journal of Family Therapy, 33(3), 210-218. doi:10.1017/ aft.2012.26

Madigan, S., Vaillancourt, K., McKibbon, A., \& Benoit, D. (2012). The reporting of maltreatment experiences during the Adult Attachment Interview in a sample of pregnant adolescents. Attachment \& Human Development, 14(2), 119-143. doi:10.1080/14616734.2012.661230

Main, M. (2000). The organized categories of infant, child, and adult attachment: flexible vs. inflexible attention under attachment-related stress. Journal of the American Psychoanalytic Association, 48, 1055-1096. doi:10.1177/00030651000480041801

Main, M., Goldwyn, R., \& Hesse, E. (2003). Adult attachment scoring and classification systems (Unpublished manuscript). University of California, Berkeley.

Main, M., Kaplan, N., \& Cassidy, J. (1985). Security in infancy, childhood and adulthood: A move to the level of representation. In I. Bretherton \& E. Waters (Eds.), Growing points of attachment theory and research, (pp. 66-104). Monographs of the Society for Research in Child Development, 50(1-2, Serial N. 209). Chicago, IL: University of Chicago Press.

Matthey, S., \& Petrovski, P. (2002). The children's depression inventory: Error in cutoff scores for screening purposes. Psychological Assessment, 14(2), 146-149. doi:10.1037/10403590.14.2.146

McCloskey, L. A., \& Bailey, J. A. (2000). The intergenerational transmission of risk for child sexual abuse. Journal of Interpersonal Violence, 15, 1019-1035. doi:10.1177/088626000015010001

McCrory, E., De Brito, S. A., \& Viding, E. (2012). The link between child abuse and psychopathology: A review of neurobiological and genetic research. Journal of the Royal Society of Medicine, 105, 151-156. doi:10.1258/jrsm.2011.110222

McGowan, P. O., Sasaki, A., D’Alessio, A. C., Dymov, S., Labonté, B., Szyf, M., ... Meaney, M. (2009). Epigenetic regulation of the glucocorticoid receptor in human brain associates with childhood abuse. Nature Neuroscience, 12(3), 342-348. doi:10.1038/nn.2270

Merckelbach, H., \& Muris, P. (2001). The causal link between self-reported trauma and dissociation: A critical review. Behaviour Research and Therapy, 39, 245-254. doi:10.1016/S0005-7967(99) 00181-3

Milot, T., Lorent, A., St-Laurent, D., Bernier, A., Tarabulsy, G., Lemelin, J.-P., \& Éthier, L. S. (2014). Hostile-helpless state of mind as further evidence of adult disorganized states of mind in neglecting families. Child Abuse \& Neglect, 38, 1351-1357. doi:10.1016/j.chiabu.2014.02.015

Nelson, C. A., Westerlund, A., Martin McDermott, J., Zeanah, C. H., \& Fox, N. A. (2013). Emotion recognition following early psychosocial deprivation. Development and Psychopathology, 25, 517-525. doi:10.1017/S0954579412001216

Neufeld Bailey, H., Moran, G., \& Pederson, D. (2007). Childhood maltreatment, complex trauma symptoms, and unresolved attachment in an at-risk sample of adolescent mothers (2007). Attachment \& Human Development, 9(2), 139-161. doi:10.1080/14616730701349721

Nilsson, D., Wadsby, M., \& Svedin, C. G. (2008). The psychometric properties of the Trauma Symptom Checklist for Children (TSCC) in a sample of Swedish children. Child Abuse \& Neglect, 32, 627-636. doi:10.1016/j.chiabu.2007.09.009

Obsuth, I., Hennighausen, K., Brumariu, L. E., \& Lyons-Ruth, K. (2014). Disorganized behavior in adolescent-parent interaction: Relations to attachment state of mind, partner abuse, and psychopathology. Child Development, 85(1), 370-387. doi:10.1111/cdev.2014.85.issue-1

Pannekoek, J. N., van der Werff, S. J. A., Meens, P. H. F., van den Bulk, B. G., Jolles, D. D., Veer, I. M., ... Vermeiren, R. R. J. M. (2014a). Aberrant resting-state functional connectivity in limbic and salience networks in treatment-naïve clinically depressed adolescents. Journal of Child Psychology and Psychiatry, 55(12), 1317-1327. doi:10.1111/jcpp.12266 
Pannekoek, J. N., van der Werff, S. J. A., van den Bulk, B. G., van Lang, N. D. J., Rombouts, S. A. R. B., van Buchem, M. A., ... van der Wee, N. J. A. (2014b). Reduced anterior cingulate gray matter volume in treatment-naïve clinically depressed adolescents. NeuroImage: Clinical, 4, 336-342. doi:10.1016/j.nicl.2014.01.007

Pascuzzo, K., Cyr, C., \& Moss, E. (2013). Longitudinal association between adolescent attachment, adult romantic attachment, and emotion regulation strategies. Attachment \& Human Development, 15(1), 83-103. doi:10.1080/14616734.2013.745713

Paus, T., Keshavan, M., \& Giedd, J. N. (2008). Why do many psychiatric disorders emerge during adolescence? Nature Reviews Neuroscience, 9, 947-957. doi:10.1038/nrn2513

Petersen, A. C., Crockett, L., Richards, M., \& Boxer, A. (1988). A self-report measure of pubertal status: Reliability, validity and initial norms. Journal of Youth and Adolescence, 17(2), 117-133. doi:10.1007/BF01537962

Pollak, S. D., \& Kistler, D. J. (2002). Early experience is associated with the development of categorical representations for facial expressions of emotion. Proceedings of the National Academy of Sciences, 99(13), 9072-9076. doi:10.1073/pnas.142165999

Putnam, F. (2003). Ten-year research update review: Child sexual abuse. Journal of the American Academy of Child \& Adolescent Psychiatry, 42(3), 269-278. doi:10.1097/00004583200303000-00006

Robertson, E. B., Skinner, M. L., Love, M. M., Elder Jr., G. H., Conger, R. D., Dubas, J. S., \& Petersen, A. C. (1992). The Pubertal Development Scale: A rural and suburban comparison. The Journal of Early Adolescence, 12(2), 174-186. doi:10.1177/0272431692012002003

Roelofs, J., Braet, C., Rood, L., Timbremont, B., van Vlierberghe, L., Goossens, L., \& van Breukelen, G. (2010). Norms and screening utility of the Dutch version of the Children's Depression Inventory in clinical and non-clinical youths. Psychological Assessment, 22(4), 866-877. doi:10.1037/a0020593

Roisman, G. I., Fraley, R. C., \& Booth-LaForce, C. (2014). Pulling ourselves up by our bootstraps: A rejoinder to Van IJzendoorn and Bakermans-Kranenburg (2014). Monographs of the Society for Research in Child Development, 79(3), 168-173. doi:10.1111/mono.12121

Sagi, A., van IJzendoorn, M. H., Scharf, M., Koren-Karie, N., Joels, T., \& Mayseless, O. (1994). Stability and discriminant validity of the Adult Attachment Interview: A psychometric study in young Israeli adults. Developmental Psychology, 30, 771-777. doi:10.1037/0012-1649.30.5.771

Sedlak, A. J. (2001). A history of the national incidence study of child abuse and neglect. Washington, DC: U.S. Department of Health and Human Services.

Sheftall, A. H., Mathias, C. W., Furr, R. M., \& Dougherty, D. M. (2013). Adolescent attachment security, family functioning, and suicide attempts. Attachment \& Human Development, 15(4), 368-383. doi:10.1080/14616734.2013.782649

Siebelink, B. M., \& Treffers, P. D. A. (2001a). ADIS-C anxiety disorders interview schedule for $D S M-I V$ (Dutch version). Lisse: Swets \& Zeitlinger BV.

Siebelink, B. M., \& Treffers, P. D. A. (2001b). Anxiety disorders interview schedule for DSM-IVChild version. ADIS-C Handleiding. Amsterdam: Harcourt Test Publishers.

Silverman, W. K., Saavedra, L. M., \& Pina, A. A. (2001). Test-retest reliability of anxiety symptoms and diagnoses with the anxiety disorders interview schedule for DSM-IV: Child and parent versions. Journal of the American Academy of Child \& Adolescent Psychiatry, 40(8), 937-944. doi: $10.1097 / 00004583-200108000-00016$

Smith, S. R., \& Carlson, E. B. (1996). Reliability and validity of the adolescent dissociative experiences scale. Dissociation: Progress in the Dissociative Disorders, 9(2), 125-129.

Steele, H., \& Steele, M. (Eds.). (2008). Clinical applications of the Adult Attachment Interview. New York: The Guilford Press.

Steele, H., Steele, M., \& Fonagy, P. (1996). Associations among attachment classifications of mothers, fathers, and their infants. Child Development, 67, 541-555.

Stoltenborgh, M., van IJzendoorn, M. H., Euser, E. M., \& Bakermans-Kranenburg, M. J. (2011). A global perspective on child sexual abuse: Meta-analysis of prevalence around the world. Child Maltreatment, 16(2), 79-101. doi:10.1177/1077559511403920

Strathearn, L. (2011). Maternal neglect: Oxytocin, dopamine and the neurobiology of attachment. Journal of Neuroendocrinology, 23, 1054-1065. doi:10.1111/j.1365-2826.2011.02228.x

Tarren-Sweeney, M. (2014). The clinical application of attachment theory and research: Introducing a series of Clinical Child Psychology and Psychiatry special sections. Clinical Child Psychology and Psychiatry, 19, 333-335. doi:10.1177/1359104514538709 
Teicher, M. H., \& Samson, J. A. (2013). Childhood maltreatment and psychopathology: A case for ecophenotypic variants as clinically and neurobiologically distinct subtypes. The American Journal of Psychiatry, 170, 1114-1133.

Timbremont, B., Braet, C., \& Dreessen, L. (2004). Assessing depression in youth: Relation between the Children's depression inventory and a structured interview. Journal of Clinical Child \& Adolescent Psychology, 33(1), 149-157. doi:10.1207/S15374424JCCP3301_14

Turton, P., McGauley, G., Marin-Avellan, L., \& Hughes, P. (2001). The Adult Attachment Interview: Rating and classification problems posed by non-normative samples. Attachment \& Human Development, 3(3), 284-303. doi:10.1080/14616730110096898

Tyrer, P. (2014, March 6). Personality dysfunction is the cause of recurrent non-cognitive mental disorder: A testable hypothesis. Personality and Mental Health. doi:10.1002/pmh.1255

van den Bulk, B. G., Koolschijn, P. C. M. P., Meens, P. H. F., van Lang, N. D. J., van der Wee, N. J. A., Rombouts, S. A. R. B., ... Crone, E. A. (2013). How stable is activation in the amygdala and prefrontal cortex in adolescence? A study of emotional face processing across three measurements. Developmental Cognitive Neuroscience, 4, 65-76. doi:10.1016/j. den.2012.09.005

van IJzendoorn, M. H. (1995a). Adult attachment representations, parental responsiveness, and infant attachment: A meta-analysis on the predictive validity of the Adult Attachment Interview. Psychological Bulletin, 117(3), 387-403. doi:10.1037/0033-2909.117.3.387

van IJzendoorn, M. H. (1995b). Of the way we were: On temperament, attachment, and the transmission gap: A rejoinder to Fox (1995). Psychological Bulletin, 117(3), 411-415. doi:10.1037/0033-2909.117.3.411

van IJzendoorn, M. H., \& Bakermans-Kranenburg, M. J. (2003). Attachment disorders and disorganized attachment: Similar and different. Attachment \& Human Development, 5(3), 313-320. doi:10.1080/14616730310001593938

van IJzendoorn, M. H., \& Bakermans-Kranenburg, M. J. (2014). Confined quest for continuity: The categorical versus continuous nature of attachment. Monographs of the Society for Research in Child Development, 79(3), 157-167. doi:10.1111/mono.12120

van IJzendoorn, M. H., Feldbrugge, J. T., Derks, F. C., de Ruiter, C., Verhagen, M. F., Philipse, M. W., ... Riksen-Walraven, J. M. (1997). Attachment representations of personality-disordered criminal offenders. American Journal of Orthopsychiatry, 67(3), 449-459. doi:10.1037/ h0080246

van IJzendoorn, M. H., \& Sagi-Schwartz, A. (2008). Cross-cultural patterns of attachment: Universal and contextual dimensions. In J. Cassidy \& P. R. Shaver (Eds.), Handbook of attachment: Theory, research and clinical applications (2nd ed., pp. 880-905). New York, NY: The Guilford Press.

van IJzendoorn, M. H., \& Schuengel, C. (1996). The measurement of dissociation in normal and clinical populations: Meta-analytic validation of the Dissociative Experiences Scale (DES). Clinical Psychology Review, 16(5), 365-382. doi:10.1016/0272-7358(96)00006-2

Vulliez-Coady, L., Obsuth, I., Torreiro-Casal, M., Ellertsdottir, L., \& Lyons-Ruth, K. (2013). Maternal role confusion: Relations to maternal attachment and mother-child interaction from infancy to adolescence. Infant Mental Health Journal, 34(2), 117-131. doi:10.1002/imhj.21379

Wallis, P., \& Steele, H. (2001). Attachment representations in adolescence: Further evidence from psychiatric residential settings. Attachment \& Human Development, 3(3), 259-268. doi:10.1080/14616730110096870

Waters, E., Merrick, S., Treboux, D., Crowell, J., \& Albersheim, L. (2000). Attachment security in infancy and early adulthood: A twenty-year longitudinal study. Child Development, 71(3), 684689. doi:10.1111/cdev.2000.71.issue-3

Wechsler, D. (1991). The Wechsler Intelligence Scale for Children-III. Canada: Harcourt Brace.

Wechsler, D. (1997). Wechsler Adult Intelligence Scale-III. San Antonio, TX: Harcourt Assessment.

Wekerle, C., Wolfe, D. A., Hawkins, D. L., Pittman, A. L., Glickman, A., \& Lovald, B. E. (2001). Childhood maltreatment, posttraumatic stress and symptomatology, and adolescent dating violence: Considering the value of adolescent perceptions of abuse and a trauma mediational model. Development and Psychopathology, 13(4), 847-871.

Westenberg, P. M. (2002). Zinnenaanvullijst (ZALC): Psychodiagnostisch gereedschap. De Psycholoog, 37(6), 316-322.

Westenberg, P. M., Jonckheer, J., Treffers, P. D. A., \& Drewes, M. J. (1998). Ego development in children and adolescents: Another side of the impulsive, self- protective, and conformist ego 
levels. In P. M. Westenberg, A. Blasi, \& L. D. Cohn (Eds.), Personality development: Theoretical, empirical, and clinical investigations of Loevinger's conception of ego development (pp. 89-112). Mahwah, NJ: Lawrence Erlbaum.

Zeanah, C. H., \& Smyke, A. T. (2008). Attachment disorders in family and social context. Infant Mental Health Journal, 29(3), 219-233. doi:10.1002/(ISSN)1097-0355

Zegers, M. A., Schuengel, C., van IJzendoorn, M. H., \& Janssens, J. M. (2006). Attachment representations of institutionalized adolescents and their professional caregivers: Predicting the development of therapeutic relationships. American Journal of Orthopsychiatry, 76(3), 325-334. doi:10.1037/0002-9432.76.3.325

Zegers, M. A., Schuengel, C., van IJzendoorn, M. H., \& Janssens, J. M. (2008). Attachment and problem behavior of adolescents during residential treatment. Attachment \& Human Development, 10(1), 91-103. doi:10.1080/14616730701868621 